\title{
Evaluation of the host preference and life history of Callosobruchus maculatus (F.) (Cowpea weevil) (Coleoptera: Chrysomelidae) on stored pulses
}

\author{
Nosheen Jehajo* and Nasreen Memon \\ Department of Zoology University of Simdh Jamshoro-Pakistan \\ *Corresponding author's email: nosheenjehajo@gmail.com \\ Citation \\ Nosheen Jehajo and Nasreen Memon. Evaluation of the host preference and life history of Callosobruchus \\ maculatus (F.) (Cowpea weevil) (Coleoptera: Chrysomelidae) on stored pulses. Pure and Applied Biology. Vol. 9, \\ Issue 4, pp2167-2174. http://dx.doi.org/10.19045/bspab.2020.90231
}

Received: 02/03/2020 Revised: 30/05/2020

Accepted: 04/06/2020

Online First: 29/06/2020

\section{Abstract}

Callosobruchus maculatus (F.) is a major store grain pest of economically important pulses in tropical and sub-tropical countries of the World. Successful survival of different geographical strains of cowpea weevil may variable on different host pulses. In present investigation, life stages of Hyderabad strain of Callosobruchus maculatus were observed on four types of stored pulses namely green gram, cowpea, chickpea and black gram at different laboratory conditions for the assessment of host preference and better management of storage. The result indicated that the Callosobruchus maculatus (F.) prefers cowpea for its oviposition, because the highest number of eggs was found on cowpea followed by green gram \& chickpea and the lowest number of eggs was observed on black gram. The highest population was recorded on cowpea followed by green gram, black gram \& chickpea. The short developmental period of cowpea weevil was observed on cowpea, green gram \& chickpea while longest was on the black gram. The longevity of C. maculatus was longer on black gram while shortest longevity was observed on cowpea and green gram. From this study it was concluded that the cowpea and green gram was most preferable host pulses for $C$. maculatus, they were also susceptible and vulnerable among all four studied stored seeds while chickpea and black gram were less preferable host and have moderate susceptibility to the Hyderabad strain of Callosobruchus maculatus (F.).

Keywords: Adaptation; Biological parameters; Damage; Infestation; Pulse beetle; Stored products protection

\section{Introduction}

Pulses (dried seeds) come in a variety of shapes, colors and sizes. They can be consumed in many forms including split or whole, in the form of flours or separated into extractions like starch, fiber \& protein. Their intake ranges from baby diet, poor's as well as delicacies of the rich; in Pakistan pulses are sowed on 1.5 million hectares of land [1]. Punjab has the major pulse growing fields followed by Sindh, Balochistan and KPK [2]. Pakistan including Sindh is facing grain storage problems since past many years, due to traditional grain storage methods or short of commercial seed storages and their management. The people in Sindh Pakistan store their grains in godowns for protection from natural enemies like insect pests, rats \& birds which cause time to time damage to the grains [3]. 
Among the insect pests, Callosobruchus maculatus (Fabricius, 1775), commonly known as cowpea weevil is a major pest of economically important pulses during field \&storage in Asia and Africa including Pakistan that presently ranges throughout the World most probably in tropical and subtropical regions with the trades and other crops $[4,5]$. This pest can infest stored pulses, including black eyed beans, mung beans, black gram, lentils, chickpea, pea nuts, adzuki beans, dry peas \& kidney beans [6]. This insect has complete life cycle with the egg and adult stage found on the seed whereas larval and pupal stage living inside the grain. The larva bore into the pulse grain; feed on the embryo and endosperm of the seed and leave behind only the seed coat, which become unsuitable for human consumption [7]. Callosobruchus maculatus (F.) survive a range of temperature and humidity; making it adaptable Worldwide except Antarctica [8]. Cowpea weevil, multiply rapidly giving rise to new generation every month under stored conditions, its damage is often very expensive and it can be very destructive to grains [9]. This notorious storage insect pest cause huge infestation to the stored product which reduce not only the quality but also the quantity of pulses.

The objective of this study is to determine the host preference and life history / life stages of Callosobruchus maculatus (F.) to different types of stored pulses. As susceptibility of cowpea weevil to pulses varies geographically and with time that's why it is important to know the host range of its Hyderabad strain so that storage planning can be made to avoid cross infestation among susceptible varieties of pulses.

\section{Materials and methods}

The study was conducted at the entomology laboratory of toxicology and pest management, Department of Zoology University of Sindh Jamshoro, under different laboratory conditions at $30-32{ }^{\circ} \mathrm{C}$,
$22-18{ }^{\circ} \mathrm{C}, 29-30{ }^{\circ} \mathrm{C}, 34-35^{\circ} \mathrm{C}$ and $60-65 \%$, 47$55 \%, 45-50 \%$ relative humidity.

\section{Stock culture of insect pest}

A small colony of Callosobruchus maculatus strain was collected from the infested cowpea seeds, which were bought from grocery shop of Tower Market Hyderabad and the cowpea weevil, Callosobruchus maculatus (F.), was identified on the basis of morphological characteristics. The collected $C$. maculatus were introduced into screened cowpea seeds in Jars, containing approximately $1 \mathrm{k} . \mathrm{g}$ seeds, which were covered with muslin cloth fastened with rubber bands. The adults were allowed to mate, oviposite and increase their progeny. The adult emergence was monitored daily and the newly emerged cowpea weevils were used to maintain the stock culture for the experimental purpose, (from August to September 2018).

\section{Experimental pulse seeds}

Four major whole pulses namely Green gram (Mung dal) (Vigna radiata), Black gram (Mash dal) (Vigna mungo), Cowpea (Black eyed beans) (Vigna unguiculata), Chickpea, (Chana dal) (Cicer arietinum) were purchased from local grocery shops of Hyderabad and tested against the Callosobruchus maculatus during storage.

\section{Preparation of the seeds for study}

The seeds were properly picked to remove plant remains, debris and dust particles. Immature and damaged seeds were removed to ensure that the used seeds had no damage or infestation before experiment. The seeds of all the pulses were then kept in freezer for one week to kill any life stages of the pest if already present on them and afterward left for $24 \mathrm{~h}$ for dry under the laboratory conditions before experiment.

\section{Experimental setup}

To assess the host preference and life history of $C$. maculatus (F.) to four different pulses, (no choice test) experiment and its control were conducted separately using the same experimental procedure. $500 \mathrm{~g}$ of screened 
pulse grains (green gram, cowpea, chickpea \& black gram) were put separately in plastic jars having $2 \mathrm{~kg}$ capacity. Five pairs of newly emerged adults of $C$. maculatus were collected from stock culture and released in each jar except control. The top of jars was covered with muslin cloth and tightly held with rubber bands to avoid the escape of beetles and provide sufficient aeration and then placed in plastic boxes for rearing under laboratory conditions for four months.

The difference in host preference and life history of cowpea weevil was evaluated by; ovipositional preference, adult emergence, developmental period and longevity of cowpea weevil. In addition to this percent weight loss and susceptibility of various host

\section{Dobie Susceptibility Index \\ $1-5$ \\ 6-10 \\ $11-15$ \\ $16-21$}

\section{Statistical analysis}

The data was statistically analyzed by Analysis of variance (ANOVA) using software version 9.0.

The procedure was followed, as described by $[11,12]$.

\section{Results}

\section{Ovipositional preference of}

\section{Callosobruchus maculatus (F.)}

For the assessment of oviposition preference, 100 seeds of all host pulses were randomly taken out from each jar containing $500 \mathrm{~g}$ of seeds and the number of eggs oviposited were counted after five days of the oviposition. After counting seeds were carefully put into their respective jars. Counting was continuing from first generation until the eggs laying for third generation.

The mean number of eggs laid on each host pulses for three successive generations (Generation 1, Generation 2 \& Generation 3), ranged from (195 to 449.3 eggs / 100 seeds). pulses to Callosobruchus maculatus was also recorded. This experiment was replicated twice, (from end of October 2018 to June 2019).

The percent weight loss of pulse grains were observed by weighing of seeds before and after experiments.

Weight loss (\%): Initial wt-Final wt X100

$$
\text { Initial weight }
$$

Susceptibility index of different pulse grains was calculated using the formula by [10].

Index Susceptibility formula:

$\underline{\log \mathrm{y} x 100}$

$$
\mathrm{T}
$$

Where $\mathrm{y}$ is the number of insects reaching adult stage and $\mathrm{T}$ is the average developmental period in days.

\section{Categories}

Resistant

Intermediate / moderate resistant

Susceptible

Highly Susceptible

Among the host pulses, the cowpea (449.3 / 100 seeds) and green gram (365 / 100 seeds) recorded highest number of eggs followed by chickpea (306.3 / 100 seeds), While the lowest number of eggs were recorded on black gram (195 / 100 seeds), during first replication (Table 1).

While in second replication the mean number of eggs laid on each host pulses ranged from (181.5 to 573.3 eggs / 100 grains). Again highest number of eggs (573.3 / 100 seeds) was laid on cowpea as compared to the other pulses. Next to cowpea higher number of eggs was recorded on green gram (478.6 / 100 seeds) followed by chickpea (463.6 / 100 seeds) and black gram (181.5 / 100 seeds), for $1^{\text {st }}, 2^{\text {nd }} \& 3^{\text {rd }}$ generation (Table 2 ).

On all the host pulses, lowest number of eggs was counted for first generation while highest number of eggs was observed for third generation due to increase number of pest population. 
Table1. Ovipositional preference of Callosobruchus maculatus (F.) to host pulses after first replication

\begin{tabular}{|c|c|c|}
\hline Host pulse & Mean average no. of eggs & Storage Period \\
\hline Cowpea & 449.3 & (Four months) \\
\hline Green gram & 365 & (From end of October to end of \\
Chickpea & 306.3 & February) \\
\hline Black gram & 195 & \\
\hline$*(\mathrm{p}<0.05)$ & &
\end{tabular}

Table2. Ovipositional preference of Callosobruchus maculatus (F.) to host pulses after second replication

\begin{tabular}{|c|c|c|}
\hline Host pulse & Mean average no. of eggs & Storage Period \\
\hline Cowpea & 573.3 & \multirow{2}{*}{ (Four months) } \\
\hline Green gram & 478.6 & \multirow{2}{*}{ (From March to June) } \\
\hline Chickpea & 423.6 & \\
\hline Black gram & 181.5 & \\
\hline
\end{tabular}

$*(\mathrm{p}<0.05)$

Mean number of adult emergence of Callosobruchus maculatus (F.)

The eggs oviposited on $500 \mathrm{~g}$ of host pulses were further kept under laboratory conditions for the emergence of adults. After the emergence of first generation (G1) on stored pulses adults were counted and allowed to oviposite for second generation (G2). After the death of G1, adults were removed. The same procedure was repeated until the emergence of third generation (G3).

The mean highest numbers of adult progeny after first replication were recorded on cowpea
(631 / 500g), green gram (492.6 / 500g) and black gram (476.5 / 500g) whereas the lowest number was found on chickpea (393 / 500g). The same results were observed after second replication the highest number of population was emerged out from cowpea (1160.6 / 500g) next to cowpea was the green gram (1038/ $500 \mathrm{~g})$, black gram $(590.5 / 500 \mathrm{~g})$ and chickpea (580.6 / 500g). The density of C. maculatus on host pulses varied among generations, the density increased continuously from G1 to G2 on all the host pulses, while the density of cowpea weevil decreased in G3 (Table 3 \& 4).

Table3. Mean number of adult emergence of Callosobruchus maculatus (F.) to host pulses after first replication

\begin{tabular}{|c|c|c|}
\hline Host pulse & Mean average no. of adults emerged & Storage Period \\
\hline Cowpea & 631 & (Four months) \\
(From end of \\
Oreen gram & 492.6 & October to end of \\
\hline Chick pea & 393 & February)) \\
\hline Black gram & 476.5 &
\end{tabular}

$*(\mathrm{p}<0.05)$

Table4.Mean number of adult emergence of Callosobruchus maculatus (F.) to host pulses after second replication

\begin{tabular}{|c|c|c|}
\hline Host pulse & Mean average no. of adults emerged & Storage Period \\
\hline Cowpea & 1160.6 & \multirow{2}{*}{ (Four months) } \\
Green gram & 1038.6 & (From March to \\
June)
\end{tabular}

$*(\mathrm{p}<0.05)$ 


\section{Developmental Period of Callosobruchus} maculatus (F.) on various host pulses

The incubation period of $C$. maculatus on each grain host was determined by the counting of first day of egg laying till the first day of adult emergence. Developmental period of Callosobruchus maculatus were observed at $30-32^{\circ} \mathrm{C}, 22-18{ }^{\circ} \mathrm{C}, 29-30^{\circ} \mathrm{C}, 34-35^{\circ} \mathrm{C}$, and relative humidity $60-65 \%, 47-55 \%, 45-50 \%$. The greatest and shortest developmental time of cowpea weevil was recorded at $30^{\circ} \mathrm{C}$ and $65 \% \mathrm{r} \mathrm{h}$, while temperature above $35^{\circ} \mathrm{C}$ and below $18^{\circ} \mathrm{C}$ and humidity below $50-45 \%$ observed the unfavorable for the growth and development of Callosobruchus maculatus.

The developmental period of cowpea weevil was faster when reared on stored seeds of Vigna unguiculata (Cowpea) followed by Vigna radiate (Green gram) and Cicer arietinum (Chickpea), Larval period was longer when Callosobruchus maculatus reared on Vigna mungo (Black gram) in comparison to $V$. unguiculata and $V$. radiate. From the two separate replications, it was observed that the mean developmental period ranged from (33.3 to 54) days in different host pulses. Cowpea, green gram and chickpea recorded the shortest developmental period, $(33.3,34.8$ and 37.5) respectively, whereas black gram recorded maximum (54) days developmental period.

\section{Longevity of Callosobruchus maculatus} (F.) on different host pulse grains

The longevity of adults was counted by the first day of adult emergence till the death. Shortest mean longevity of Callosobruchus maculatus was recorded (11.5, 12.8 \& 13.5), days on cowpea, green gram and chickpea respectively, while its longest mean longevity (17) days was observed on black gram.

The weight loss (\%) and susceptibility index following infestation by Callosobruchus maculatus (F.) to stored pulses

The weight loss (\%) and susceptibility index were determined in separate set of replications and the data pertaining to the experiments on four different pulses was presented in (Table 5) revealed that the Grain weight loss among the host pulses ranged from (34\% to $58 \%$ ) after first replication. Black gram recorded the significantly lowest weight loss $(34 \%)$ while the highest weight loss was recorded from cowpea (58\%), followed by green gram (57\%) and chickpea (37\%), While after the second replication cowpea recorded the significantly highest weight loss of grains $(62 \%)$ followed by green gram $(61 \%)$, chickpea $(56 \%)$ and black gram $(50 \%)$.

The susceptibility index showed that the cowpea (11.7) with significantly susceptible followed by green gram (11) which was considered to be the next susceptible. Both of the pulses can be enlisted under susceptible class. Lower susceptibility index was noted from black gram (6.2) followed by chickpea (9.2), they both have found moderately resistant to the Hyderabad strain of Callosobruchus maculatus (F.).

Table 5. The weight loss (\%) and susceptibility index following infestation by Callosobruchus maculatus (F.) to stored pulses

\begin{tabular}{|c|c|c|c|c|}
\hline Pulse & $\begin{array}{c}(\%) \text { wt. loss } \\
\text { after 1 }^{\text {st }} \\
\text { replication }^{\text {Cownea }}\end{array}$ & $\begin{array}{c}(\%) \text { wt. loss } \\
\text { after 2 } \\
\text { replication }^{\text {nd }}\end{array}$ & $\begin{array}{c}\text { Susceptibility } \\
\text { index }\end{array}$ & Categories \\
\hline Cowpea & $58 \%$ & $62 \%$ & 11.7 & Susceptible \\
\hline Green gram & $57 \%$ & $61 \%$ & 11 & Susceptible \\
\hline Chickpea & $37 \%$ & $56 \%$ & 9.2 & Intermediate/ moderate resistant \\
\hline Black gram & $34 \%$ & $50 \%$ & 6.2 & Intermediate/ Moderate resistant \\
\hline
\end{tabular}




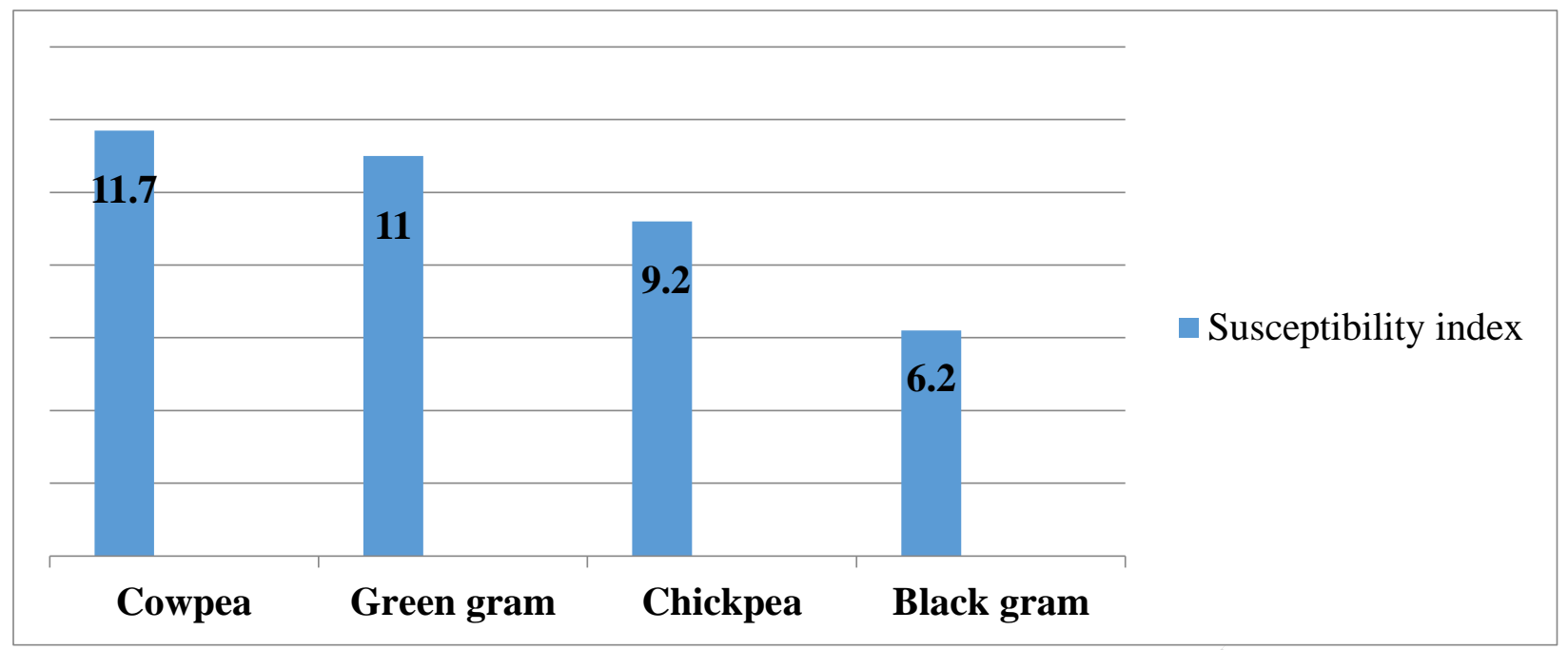

Figure 1. Relative susceptibility of various host pulses to Callosobruchus maculatus (F.)

\section{Discussion}

The results of the present experiments were comparable with those reported by $[11,12]$. The statistics showed that the data of current investigation was highly significant. [12] Recorded that Callosobruchus maculatus (F.) had highest number of eggs laid and adult survival on cowpea and green gram followed by red gram and field bean. While in present experiments among different host pulses cowpea and green gram had maximum number of eggs followed by chickpea and black gram, so based on fecundity the order of host preference was cowpea > green gram $>$ chickpea $>$ black gram. Cowpea and green gram has smooth skinned seed texture that probably supports the cowpea weevil to prefer for more eggs laying. Highest adults were also emerged out from cowpea and green gram. Black gram \&chickpea had lowest number of adults possibly due to hard outer covering which prevent larvae to bore inside the grains. The findings were in conformity with [13] who concluded that the oviposition preference of the family bruchidae might be concerned with smoothness of seed coat and size of grain. The result obtained in this study further explained the observation of [9] who reported that the temperature and humidity was frequently the two of the mainly important environmental factors affecting the population dynamics of Callosobruchus maculatus during storage. They observed the fecundity and developmental time of $C$. maculatus and its parasitoid (Dinarmus basalis) during dry season at the two different regions under natural conditions and recorded that at the beginning of dry season (December to February) the climatic conditions influence a phase of slow population growth in the stores of both zones due to low temperature and humidity and it was the temperature and humidity rose from March onward which allowed the increase of the bruchid density by reducing the developmental time. Our results are close to the findings of [9] that during first replication in the month of October-November when temperature was $\left(30-32^{\circ} \mathrm{C}\right)$ and humidity (60$65 \%$ ), recorded the favorable for oviposition, adult emergence and longevity of cowpea weevil. Developmental time was also short at this temperature and humidity. While during the December to February when temperature and humidity was going to fall $\left(22-18{ }^{\circ} \mathrm{C}\right) \&$ (47- 55\% $\mathrm{r} \mathrm{h}$ ) the life activities and reproduction of Callosobruchus maculatus first slow down and then stopped, at this low temperature development period was longer because larval and pupal stages undergo hibernation while eggs and adults were died, 
on return of favorable condition by the end of February these immature stages emerged out as adults. While during second replication in the month of March and April recorded favorable temperature and humidity (29$\left.30{ }^{\circ} \mathrm{C}\right) \&(60-65 \% \mathrm{r} \mathrm{h})$, it increased the population by reducing the development time, when it was rose the temperature (34$\left.35^{\circ} \mathrm{C}\right)$ and decrease the humidity $(45-50 \%)$ by the end of May to June, it decrease the reproduction activities of Callosobruchus maculatus. [11] Reported that cowpea weevil had shortest developmental time on cowpea (26 days), green gram (27.25 days) and Small pea (28 days), and longest on kidney beans (35.25 days) followed by black gram (29.5 days). Our results showed, the mean developmental time period of $C$. maculatus was depending on host pulses it was longer when cowpea weevil reared on black gram (54 days), and shorter when reared cowpea (33.3 days), green gram (34.8 days) \& chickpea (37.5 days). It was also observed that the longevity of Callosobruchus maculatus was depending on the development period when it was longer longevity of cowpea weevil was also longer. Highest weight loss percent was recorded from cowpea and green gram followed by chickpea and black gram. Similar order was recorded in case of susceptibility index, Cowpea and green gram found susceptible and most favorite host pulses while chickpea and black gram was less preferable and moderately resistant stored pulses to the growth and development of Callosobruchus maculatus (F.) (Cowpea weevil). This result was accordance to [12] who worked on $C$. maculatus and $C$. analis and [14] who worked on $C$. chinensis.

\section{Conclusion}

From this study it was concluded that the cowpea seeds are the most sensitive pulse seeds and most suitable host for Callosobruchus maculatus (F.). This host seeds had the maximum number of eggs laid, higher adult emergence, shortest developmental period, maximum weight loss and had susceptible index, followed by green gram as suitable for infestation. Chickpea and black gram was less favored and moderately resistant. The current research findings provide the way of awareness to the formers not to store cowpea, green gram and other susceptible seeds in the same place and at the same time at appropriate temperature and humidity of stores, it will help to avoid cross infestation among susceptible stored pulses.

\section{Authors' contributions}

Conceived and designed the experiments: $\mathrm{N}$ Jehajo \& N Memon, Performed the experiments: $\mathrm{N}$ Jehajo, Analyzed the data: $\mathrm{N}$ Jehajo, Contributed materials /analysis / tools: Entomology laboratory of toxicology \& pest management, Department of Zoology University of Sindh Jamshoro, N Memon \& N Jehajo, Wrote the paper N Jehajo.

\section{References}

1. Pakistan Agricultural Research Council (2012). www.parc.gov.pk

2. Pakistan Agri Business (2013). www.agribusiness.com.pk

3. Tunio DS (2002).Grain storage problems in Pakistan. Pakistan and Gulf Economist (issue 36). www.fao.org/t1838e/T1838E05.htm

4. Park C, Kim SI \& Ahn YJ (2003). Insecticidal activity of asarones identified in Acorus gramineus rhizome against three coleopteran stored-product insects. $J$ of Stored Prod Res 39(3): 333-342.

5. Mulatu B \& Gebremedhin T (2000). Oviposition deterrent and toxic effects of various botanicals on the Adzuki bean beetle, Callosobruchus chinensis L. Insect Sci and Its Appl 20(1): 33-38.

6. Beck CW \& Blumer LS (2013). Life cycle of Bean Beetles, Callosobruchus maculatus (Coleoptera: Chrysomelidae). Published online at www.beanbeetles.org

7. Singh SR \& Jackai LEN (1985). Insects pests of cowpea in Africa; their life cycle, economic importance, and potential for 
control. In Singh, SR and Rachie, ko (eds.), cowpea research, Production and utilization chichester. John Wiley \& Sons, pp 217-231.

8. Beck CW \& Blumer SL (2014). A hand book on bean beetles Callosobruchus maculatus. $1^{\text {st }}$ Ed. 3-5 p. Department of Biology Emory University and Department of Biology More house College.

9. Ouedraogo AP, Sou S and Sanon A, Monge JP, Huignard J, Credland PF, Tran B (1996). Influence of temperature and humidity on population of $C$. maculatus (Coleoptera: Bruchidae) and its parasitoid Dinarmus basalis (Peteromalidae) in two climatic zones of Burkina Faso. Bull Entomol Res 86: 695-702.

10. Dobie P (1974). The laboratory assessment of the inherent susceptibility of maize varieties to post- harvest infestation by Sitophilus zeamais Motsch (Coleoptera: Curculionidae). J of Stored Prod Res 10: 183-197.
11. Chakraborty S, Mondal P\& Senapati SK (2015). Evaluation of relative susceptibility of Callosobruchus chinensis Linn. On five different stored pulse seed. Pelagia Research Library. Asian $J$ of Plant Sci and Res 5(10): 9-15.

12. BK Shivanna, BN Ramamurthy, B Naik Gangadhara, S Devi Gayathri, H Mallikarjunaiah \& R Naik Krishna (2011). Host preference of pulse beetles, Callosobruchus maculatus (Fab.) and $C$. analis (Fab.) on selected pulses. Inter $J$ of Sciand Nat 2(2): 238-240

13. Girish GK, Singh K \& Murthy K (1974). Studies on ovipotion and development of Callosobruchus maculatus (Fab.) on various stored pulses. Bull Grain Tech 12: 113-116.

14. Sarwar M (2012). Assessment of resistance to the attack of bean beetle Callosobruchus maculatus (Fabricius) in chickpea genotypes on the basis of various parameters during storage. Songklanakarin J of Sci and Technol 34 (3): 287-291. 